\title{
Lo sublime y lo impensado en la apuesta vanguardista de Miltín 1934 de Juan Emar
}

\section{The Sublime and the Unforeseen in Miltín 1934, an Avant-garde Novel by Juan Emar}

\author{
Malva Marina Vásquez \\ Instituto de Literatura y Ciencias del Lenguaje. Pontificia Universidad Católica de \\ Valparaíso, Chile \\ malmara@msn.com
}

Resumen • En Miltín 1934 de Juan Emar se despliegan dos concepciones de lo sublime. Un sublime hecho estereotipo, un arte para el buen burgués, inscrito dentro de una estética mimética de corte naturalista. Emar realiza una sátira de este tipo de arte y de la crítica de arte nacional que imperaba en la época. Su apuesta vanguardista promueve una estética de lo sublime como negación del efecto referencial y apertura a lo impensado foucaultiano. Esta estética en Miltín 1934 se configura como la tentativa de una escritura imposible y un esbozo de una poética de lo fluídico-inusitado, propuesta que Emar desarrollará a cabalidad en su obra póstuma Umbral.

Palabras clave: Juan Emar, lo sublime, lo impensado, apuesta vanguardista, Miltín 1934.

\begin{abstract}
In Miltín 1934 Juan Emar unfolds two conceptions of sublime, considering this concept as a stereotyped fact, an art for bourgeoisie consumption, kept within a mimetic and naturalistic aesthetics. Emar satirizes this type of art as well as the art-critique that was dominant in the country at the time. His avant-garde proposal endorses an aesthetic of the sublime as a denial of the referential effect, which opens to Foucault's Unforeseen (yet-not-thought). The aesthetic of Miltin 1934 is an attempt of an impossible writing, and an outline for the aesthetics of a fluent unexpected poetic, proposal that Emar will fully develop in his posthumous work, Umbral.
\end{abstract}

Key words: Juan Emar, Sublime, Avant-garde, Aesthetic, Unforeseen, Miltín 1934. 


\section{INTRODUCCIÓN}

Sin lugar a dudas que como una apuesta riesgosa podríamos calificar el intento escritural de Juan Emar en Miltín 1934․ . Ello porque enmarcado en la tónica contestataria de la vanguardia, se jacta de contravenir toda clase de preceptos, en lo que dice relación con el modelo narrativo hegemónico en el ámbito literario chileno. Su intento de posicionar la vanguardia en una modernidad periférica, cuya primera trinchera de combate se dio a través de sus Notas de Arte en el diario La Nación, nuevamente se frustra, dado el precario estado del campo cultural chileno del período ${ }^{2}$. En su escrito primerizo Cavilaciones (1923), texto cuyas aristas autobiográficas ofrecen interesantes claves de lo que se irá consolidando como su singular y hermética poética, ya hallamos las primeras pistas de lo que será su particular y radical manera de entender el compromiso artístico ${ }^{3}$. Buscando un parangón con otro escritor vanguardista chileno, Vicente Huidobro, tenemos que a ambos: «En las trincheras del arte nuevo les unió la audacia ante la hostilidad de la crítica, el desafío nietzscheano a la «moral del rebaño> y una aguda conciencia del lenguaje estético que, iniciada en torno al cubismo, se escabullía de las estrechas demarcaciones» (Castro, 150). De modo que de la recepción crítica de ésta, su obra Miltín 1934, se puede decir que el poder silente que (no) ostentó dentro de su campo literario se vio opacado, y en términos de lo canónico, a causa de su mismo brillo. Es la casi nula recepción de esta obra por parte de la crítica de la época la que la valida como una potentísima contracrítica de la nacional, siendo aquel brillo, entonces, su actual revalorización, tentativa de la cual el presente artículo también se hace cargo. De hecho, fue aquel mutismo de sus coetáneos el que proporcionó la fuerza con que hoy en día irrumpen en escena un sinnúmero de voces que reivindican la obra de quien por aquel entonces diría de sí mismo: «Este tipo de 1934 era en realidad estupendo» (Emar, Miltín 1934, 42).

En esta nouvelle se advierte que, ya sea mediante el uso iterativo de la digresión del narrador sobre la imposibilidad del proceso escritural mismo, o en los comentarios en contra de la crítica nacional tanto artística como literaria - todo esto, tamizado por la más cruenta de las sátiras a las sociedades artísticas del momento en Chile 4 - converge un ideario cuya motivación es la búsqueda de lo desconocido, lo impensado, lo diferente o lo inusitado, como movimiento experimental en el que se aventuran los ismos y conditio sine qua non de su validez artística. De ahí que en Miltín nos diga su narrador, tras ir a distintos bares con su mujer y un amigo: «[...] toda vuelta a lo mismo, toda insistencia, nos era punto menos que fatal. [...] es romper lo que somos, es negar la existencia de todo círculo, es afirmar nuestra potencia de libertad por el hecho mismo de ir adonde no debemos ir» (19). Esta opción por la diferencia es explícita en las vanguardias, para las cuales «Repetir es ir contra las formas del espíritu, contra su fuga hacia adelante» (Picasso, 13),

1 La primera edición de esta obra fue publicada en 1934 por la Editorial Zig-Zag. Para efectos de citaje en este artículo, sin embargo, se utilizará la que aparece en la bibliografía.

2 Para la relación entre modernidad periférica y arte de vanguardia en Chile, véase Lizama, «Un año».

3 Al respecto, Peter Burger señala que el compromiso en el arte se suscita en pos de una ruptura de las fronteras del tradicional binomio productor/receptor, funcionando el artista como un teórico de su propia praxis. Así, y en relación a la obra de arte: «esta producción no puede entenderse como producción artística, sino que ha de interpretarse como parte de una praxis vital emancipadora» (Burger, 108).

4 Plaza señala al respecto: «Miltín 1934 abunda en señalamientos de este tipo. Nombra personas, medios de prensa, artistas, todo, para formular una serie de críticas a vicios institucionalizados en el ámbito de la cultura. En este sentido, se construye en cuanto ideario de desafío a los poderes y el saber oficializados». 
lo que nos recuerda la propuesta rupturista del formalista ruso Shklovsky ${ }^{5}$, para quien la experiencia artística implica la búsqueda de una percepción desautomatizada de la realidad y, por lo tanto, la constante renovación de las formas artísticas. Movimiento de cambio que la vanguardia lleva al paroxismo, hasta conducir a la paradoja de consolidarse como «la tradición de la ruptura» (Paz). En Miltín 1934, dicha búsqueda se convierte en la proclama del grupo de amigos, para quienes ser un cronista de lo que rompa con la «Gran Costumbre» (Cortázar) es transmutar la vida misma en experiencia artística. De ahí que la literatura ya no se entienda sólo como una producción en cadena de obras, sino que forme parte de una serie de prácticas sociales, como la bohemia, las tertulias de café y el acto mismo de escritura entendido como un "proceso" artístico. Por ello la contemplación de un «avión ebrio» — esto es, un vehículo que niega su función utilitaria de llevar a un destino fijo- lleva al narrador a consignarlo en esa bitácora del acontecer poético: «El [día] de hoy ya ha sido diferente... al marcar el reloj las 6.38 hemos presenciado el más inusitado espectáculo» (20). Será en ese "avión ebrio», cuyo itinerario es azaroso y discontinuo, que páginas más adelante el narrador iniciará un vuelo interplanetario con su amigo el Capitán Angol, para visitar a Dios mismo ${ }^{6}$.

Esa fuga de todo lo ya etiquetado, de lo ya cosificado "en la costra del concepto» (Adorno), podría ligarse a lo que para Lyotard será el entendimiento de las vanguardias desde la perspectiva de lo irrepresentable, lo que, como veremos en el presente artículo, las enmarca dentro de una estética de lo sublime: "La modernidad, cualquiera sea la época de su origen, no se da jamás sin la ruptura de la creencia y sin el descubrimiento de lo poco de realidad que tiene la realidad, descubrimiento asociado a la invención de otras realidades. [...] Pienso, en particular, que la estética de lo sublime encuentra en el arte moderno (incluyendo la literatura) su fuerte, y la lógica de las vanguardias sus axiomas» (Lyotard, 20). Lo irrepresentable, en este caso, se asocia con la ruptura con todo aquello que, para los vanguardistas, pecaba de representable. Así, esta estética de lo sublime entra en franca confrontación con la estética mimética de corte naturalista de las artes nacionales?.

Es así, entonces, que nuestra lectura de Miltín 1934 recorrerá dichas páginas buscando las pistas de la latencia en ella de una estética de lo sublime, entendido dicho concepto desde dos muy diversas aristas. Por una parte encontraremos la franca diatriba de lo que es el uso y abuso de un «sublime» ya degradado, hecho cliché o estereotipo en la crítica

Para Shklovsky, la función del arte es liberar el objeto de los automatismos perceptivos: «La automatización devora los objetos, los hábitos, los muebles, la mujer y el miedo a la guerra. [...] Para dar sensación de vida, para sentir los objetos, para percibir que la piedra es piedra, existe eso que se llama arte» (Todorov, 60).

6 La caracterización de Dios en este episodio desacraliza las representaciones estereotipadas sobre lo inefable. Es por ello que el narrador, tras inquirir al Capitán Angol sobre su regreso a la tierra, en un final en que ocurre un salto metaléptico en que retorna abruptamente al acto de narrar mismo, señala aliviado: «¡Bendito momento! Porque ya no toleraba más en tan exquisito e inefable sitio; porque ya estaba más arriba de la coronilla con aviones [...] y qué sé yo; y porque ya, [...] de páginas atrás, venía buscando cómo aterrizar decentemente en este cuaderno» (Emar, Miltín 1934, 54).

7 Distingue nuestro autor entre una literatura Bluff, la que se centra en las peripecias de personajes — de allí que lo mimético tenga carácter de accesorio- en donde se focalizará la atención del lector burgués, y una literatura verdadera, la que «Evita este trabajo superfluo: alrededor nuestro hace un mundo en el que cuanto suceda, no habría podido dejar de suceder. Y esta fatalidad o lógica, este rigor y concentración es lo que causa la sensación de total realidad, aunque nada ni siquiera parecido pudiésemos hallar en nuestros recuerdos o conocimientos». No es casual que, posteriormente, Umbral se acoja fielmente a esa descripción (Emar, Ideas sueltas sobre Literatura, 5). 
nacional; por otra, la reivindicación de lo que será una estética de lo sublime, concebida como praxis de una verdadera apuesta vanguardista, en la cual la consigna emariana se condensa en su necesidad de «jugarse el todo entero» (Emar, Miltín 1934, 212). Esta última concepción es la que da cuenta del elemento utópico de la vanguardia: la idea de un arte absoluto y de una obra de arte total, entendida como una «superación real de la reificación y división de las artes, pero también como posibilidad de integrar al individuo en una cultura sobre la base de valores estéticos» (Subirats, 96). Para Lizama, es esencial ese elemento utópico en la poética de Emar: «La posición emariana entonces se distancia del color local y del realismo socialista para postular un pensamiento crítico que, autónomo y situado, se enfrenta al infinito. No es casual la opinión de Emar en 1935 acerca del panorama literario chileno; para él, lo importante es que «cada día se levanta una nueva vela y se aleja sin miedo hacia lo desconocido, hacia el infinito y eso me basta> [...]» («Un año», 106).

De ahí que, recurriendo al procedimiento cubista del montaje en Miltín 1934, la serie de apariciones de Martín Quilpué, en diferentes momentos del devenir narrativo cumplen la función de ritornello existencial y puesta en abismo de la concepción vanguardista del artista, de su praxis vital. El artista -Martín Quilpué- con su mero pasar en diferentes hábitats, provoca un efecto de shock al alterar los órdenes tanto naturales como culturales. Dicho efecto de la praxis del artista es lo que Emar llamará «lo inusitado» en diversos pasajes del relato, lo cual está fuertemente vinculado al efecto del asombro que provoca lo fantástico. Esa utilización de elementos fantásticos como recursos tendientes a la mostración de la revolución ejercida por las vanguardias contra la práctica mimética es bosquejada por Patricia Espinosa en los siguientes términos:

El narrador en su continuo reflexionar se enfrenta a un mundo cotidiano intervenido por lo fantástico. Es decir, lo fantástico opera como un dispositivo que le permite acceder a situaciones donde se potencia el análisis y le permite auscultar las fracturas de lo realcotidiano. Advierto en tal actitud la filiación de Emar con el surrealismo; en tanto existe un orden racionalista, causalista, coexistiendo con un orden otro, plagiado de anomalías, situaciones ilógicas (Espinosa, 113).

Comentario respecto al cual habría que agregar que esas «fracturas de lo real-cotidiano» no sólo se producen en el mundo «objetivo», o sea vienen desde afuera, sino que en su mayor parte son intervenciones del artista, creadoras de nueva realidad. El artista, entonces, es quien irrumpe en la realidad aparente, instaurando lo inusitado como la auténtica percepción artística. Es decir, lo que aquí se presenta como lo inusitado sería aquella intervención de Martín Quilpué ${ }^{8}$ en el espacio de las costumbres arraigadas, alterando el orden de lo familiar. No por nada es que a cada una de sus apariciones la (dis) continuidad del relato asuma un cambio brutal de su dirección.

8 Las apariciones de Martín Quilpué pueden explicarse desde la técnica del montaje, asociada al cubismo, el cual, en palabras de Cantin, proponía que: «en lo figurativo, la presencia unificadora del modelo era sustituida por el montaje de elementos heterogéneos, tomados de regiones inconexas de lo real» (Enciclopedia Universales, 456. cit. en Cantin, 100). En ese sentido, Martín Quilpué funciona como un eje (re) articulador de una estructura en découpage, en donde lo único iterativo, son sus apariciones. 


\section{SOBRE LA CRÍTICA CANÓNICA COMO DISCURSO INQUISITIVO: LO SUBLIME ENTENDIDO COMO "SANTA COMODIDAD" Y SU RELACIÓN CON LAS VANGUARDIAS}

Los artistas han olvidado la vida, han olvidado ser y se nutren de
enseñanzas caducas.

Juan Emar, «Arte Infantil», Notas de Arte

En Miltín 1934, el narrador mantiene un fructífero diálogo con el pintor Rubén de Loa respecto de lo que ambos entenderán por arte. Por una parte, aquel arte destinado al consumo, de donde un artista-proveedor crea para su receptor idóneo, el burgués-reposado, un objeto artístico que satisface desde gustos transitorios hasta la necesidad de colgar en sus muros «una ambición frustrada, una añoranza, una esperanza [...]» (Emar, Miltín 1934, 203). El arte burgués, por lo demás, se asocia inevitablemente a la perpetuación de los cánones tradicionales, en contraposición a todo atisbo de avant-garde: «es preferible mil veces una mujer de Tiziano a un desnudo cubista» (Emar, Miltín 1934, 204).

Ya en ese primer acercamiento nos hallamos, en primer lugar, ante aquel falso sublime que para Emar radica en un mero guiño acomodaticio al arte por parte de la burguesía. Frente a esta musealización de la experiencia artística, De Loa plantea la existencia de un arte: «Como un medio más para que el hombre se realice, amplíe su campo de visión y comprensión, ajeno, totalmente ajeno, a sus pequeñas miserias cotidianas. [...] para abrir nuevas posibilidades humanas, y el artista que lo hace obliga, a quien quiera tocarlas, a subir hasta él y a tener el coraje de afrontar lo que venga, aunque atropelle y revuelque sus pequeñas aficiones y pequeñas costumbres» (Emar, Miltín 1934, 218).

Esa preocupación del artista vanguardista por la problemática del consumo se circunscribe dentro de la inquietud que despierta en las vanguardias el advenimiento de la modernidad, en particular, lo referente a la entronización del gran mercado capitalista mundial y los Estados cada vez más poderosos y burocráticos. Lo contradictorio de los temps moderns, asociado juntamente a la pluralidad misma de dicho movimiento, es lo que Subirats inscribe dentro de una estética cartesiana, por cuanto el arte moderno presentaría una dualidad entre «una duda absoluta y una absoluta ruptura de la tradición y el pasado en general, y por otra parte, (sobre) la voluntad positiva de construir un edificio firme de conceptos y valores universales» (Subirats, 100). De hecho, Emar señala en una de sus notas de arte esa ruptura total con la tradición para ir a la búsqueda de una nueva verdad: "Cada artista de verdad tiene, por sí solo, que rehacer para sí toda la historia del arte» (Notas de arte, 128). Dicha duda, para Emar, se teñirá de una fuerte preocupación moral: la de servir como férreo puente de denuncia de la modorra con la que los doctores de la ley de aquel entonces validaban la quística petrificación de sus cánones. De allí que señale, con evidente ironía:

no hay que ir más a ningún Salón, a ninguna Exposición, a ningún Museo. Es preferible comprar nuestra santa prensa y constatar en ella [...] que junto a nosotros [...] crece [...] la obra elevada que nos levanta del lodo cotidiano y nos aleja del espectro de la fealdad. Aunque no nos movamos de nuestra habitación, saber tal cosa fortifica la fe en la grandeza humana. En cambio, si en lugar de contentarse con la santa prensa se va uno a tocar con el índice tanta belleza, para ver y creer, penetra por la epidermis una diabólica duda, un enroscado punto de interrogación (Miltín 1934, 187). 
Miltín 1934, como potente (contra)crítica de la crítica nacional, se alza contra ella señalando su errada perspectiva, la que afecta el encuentro directo del hombre con el arte mismo. La crítica había pasado de ser mediadora a ser el objeto de lo que, en ese entonces, la academia definía como arte. El medio, entonces, había ocupado el sitial de la finalidad misma, que es el arte en estado puro, es decir, la directa relación del objeto artístico con sus posibles receptores. Es al comienzo del último episodio de Miltín 1934 en donde Emar explicita, de modo irónico, sus ideas respecto a ese falso sublime que difunde la crítica de arte nacional: "iQué bien me siento bajo tanto cántico a lo que en este mundo es puro ideal, divino! [...] ¡Y cuánta falta me hacía este baño de palabras inefables a las inefables bellezas de las artes! Pues, te diré, me sentía agobiado, aplastado y reventado de ver tanto sublime en tan poco tiempo» (186-187). Así, Emar comienza su largo diálogo con el pintor Rubén de Loa, al parapetarse, ambos, en una suerte de choza creada sólo con una multitud de recortes de la crítica de arte del diario El Mercurio ${ }^{9}$. El narrador, tomando como marco los postulados de Slavinsky, denuncia un hecho clave: la función operacional de la crítica, al servir como mediadora entre la obra y el público. Si la crítica sirve al objeto artístico en sí, a fin de que toque a una mayor cantidad de receptores, el problema que visualiza aquí Emar es la transformación de la crítica en una institución que no está eminentemente al servicio del arte, sino de sí misma. Es por ello que, de modo sarcástico, el narrador insta a no visitar más ningún museo ni galería, por cuanto es la crítica, en su función postulativa ${ }^{10}$, aquella que estaría encargada de determinar, en la práctica, qué debe ser considerado arte y qué no.

Nuestro autor acuña la sigla «d.p.a.n.s» —en minúscula, en un afán desacralizador - donde acuartela a todos los académicos que practican: la defensa pro arte nacional sublime. Satiriza con ello la necesidad planteada por sus enemigos de omitir absolutamente todo influjo artístico extranjero: "Lo hacemos como defensores genuinos de nuestra tradición artística elevada en sus más altos ideales» (Emar, Miltín 1934, 187. La cursiva es nuestra). En dicho sentido, ese falso sublime se liga a la necesidad de instaurar un arte netamente nacional ${ }^{11}$, alejado de toda posible imitación de los antiguos modelos. Es curiosa la contradicción que Emar evidencia

9 Recordemos que Emar, desde La Nación, inicia su contracrítica al diario por excelencia de aquel entonces. De allí que arremeta en contra de los dos baluartes más importantes de la crítica de ese entonces: el realismo y la necesidad de un arte eminentemente nacional. De quemarse la choza, hecha de falso sublime, es decir, la crítica imperante, no tendrían más remedio, como receptores comunes, que enfrentarse a la realidad: «[El narrador a Rubén de Loa] Así es que, te repito, no fumes. Piensa que centímetros más allá es la Alameda. Y la Alameda trae consigo la realidad, y la realidad trae... Quedémonos aquí. Y ahora escucha el murmullo de estos papeles» (Emar, Miltín 1934, 187).

10 La función postulativa, al direccionar y emitir juicios acerca de qué debe ser considerado arte, deja de ser, según Emar, una función, para erigirse como el objeto mismo del análisis. Slavinsky señala respecto de dicha función que sus operaciones cognoscitivo-interpretativas van generando su objeto. El problema es que esa dinámica se hiperboliza, pasando la función descrita a considerarse como el arte mismo. En Miltín 1934, un ejemplo de ello es el de la ulterior canonización del impresionismo: «A su aparición, los doctores de lo inefable de aquel tiempo, los d.p.a.n.s [...] salieron a las calles a garrotazos, blandiendo una furia tan imponente [...] ¡Imagínate! Todo el arte de consumo estaba tranquilito, cada buen varón encontraba [...] su dosis de consuelo [...] y de pronto aparecen estos atrevidos mancebos asegurando cosas capaces de revolcarle los sesos al más insensato: ¡La naturaleza podía considerarse de otro modo! [...] Pero vino la costumbre, los artistas-proveedores aprendieron a hacer impresionismo" (Emar, Miltín 1934, 210).

11 De ahí el juego irónico que en páginas anteriores Emar hará con sus cuentos «Español», «Inglés» y «Francés», mediante los cuales busca disculparse de la falta de color local de la que, hasta el minuto, adolecía su relato. Baste recordar la narración y posteriores que dan título a la novela. 
en los críticos, puesto que ellos, no obstante ceñirse a innumerables reglas de corte clásico, niegan todo influjo que no sea nacional ${ }^{12}$. Es así que frente a todo lo que sea nuevo, y por ende considerado como un peligro, "los doctores de lo inefable de aquel tiempo, los d.p.a.n.s, los burgueses-reposados y los artistas-proveedores salieron a las calles a garrotazos, blandiendo una furia tan imponente como la que hoy acomete a los colaboradores de la santa prensa»(Emar, Miltín 1934, 210).

Este sublime hecho cliché se alza contra el peligro avasallante de los «ismos`, los que para los burgueses atentan contra la santa comodidad: "En nuestro ambiente [...] ha habido una ligerísima trepidación. Y se dio la voz de alarma. La alarma por el peligro que corría la santa comodidad [...] [la que] se creyó amenazada en sus fueros por los monstruos de la libertad, llamados vulgarmente los ismos»» (Emar, Umbral, 70). De ahí que Miltín 1934, al igual que la tónica general de las Notas de Arte, transite entre los dos extremos de un péndulo. Por una parte, haciendo gala de un profundo desdén por las pautas congeladas de aquel sector mayoritario de la crítica, anquilosada en sus rectos principios; por otra, en franca defensa de lo que en El Globo de Cristal aparece bajo una estética que concibe: «El arte como un estallido» ${ }^{13}$ : es decir, como una praxis vivificante por sus propiedades señeras de profunda y temeraria exploración. Es esto último, entendido como un periplo hacia la búsqueda de la verdadera vida, alejada de la comodidad del arte burgués, a lo que Emar apela tajantemente: “¡Nada de inquietudes! ¡Qué decir de rebeliones! Es un arte pacífico al servicio de todos los hombres resignados que viven con el tic-tac del reloj y que, entre sombras, recuerdan apenas —acaso allá en la juventud, acaso en la infancia, acaso en otra existencia- que hubo alguna vez dentro de sus pechos un comienzo de hálito rebelde, un comienzo de tormenta, una exaltación, un dolor. Es decir, Vida» (Emar, Miltín 1934, 208).

Todo aquello que signifique una posible pauta de evolución es considerado un inminente peligro a sortear por parte de la Academia, según Emar, dado que ella es un símbolo prominente de lo canónico. En Miltín 1934 esto se materializa en las punzantes críticas del narrador hacia el Centro de Bellas Artes. De allí que el método idóneo de hacer crítica, es que se «escribirá única y exclusivamente [...] sobre aquellas obras que le hayan entusiasmado, locamente entusiasmado, o bien le hayan horripilado hasta las náuseas» (44). Por su parte, el tema de los cuadros resulta idóneo para nuestro autor, por cuanto sus límites, materializados en sus marcos,

12 «Nuestra tradición se quiebra... Nuestra originalidad se empaña bajo influencias ajenas, influencias del viejo mundo [...] Fidias está inquieto, en la Chimba; Rembrandt tiembla, junto al Mapocho [...] Miguel Ángel está triste en la Avenida Matta. ¿Qué tendrá Miguel Ángel? Influencias ajenas ¡en Chile! Jamás, desde Almagro a nuestros días, habíase visto semejante cosa. Miguel Ángel está triste. ¿Qué tendrá Miguel Ángel?» (Emar, Miltín 1934, 188-189). Lo parcelado de las opiniones de los pertenecientes a la d.p.a.n.s es ridiculizado en un sinfín de ocasiones: «Es como si yo mañana hiciese una gran torta de crema Chantilly, chocolate y manjar blanco, y la adornara con espejuelos multicolores y palomitas de porcelana... ¿a quién imito? Naturalmente, ¡A nadie! ¿A Ramis Claire? No, por cierto, pues él pone conejitos de vidrio. [...]. ¿A las tortas parisinas? ¡Imposible! En París no usan manjar blanco. Y así hasta el infinito. ¡No imito a nadie! ¡Es mi personalidad!» (Emar, Miltín 1934, 220).

13 «¡Oh, sí! Quien mesura se encalaboza; quien cae en calabozo ya no tiene que ocuparse en buscar mesura. Y esto es verdad: cuantos se hallan encalabozados solo piensan en descalabozarse, en evadirse, en dilatarse por calles, por carreteras, por ferrovías, por lo que sea con tal de que ello sea largo, interminable y hacia todos lados a la vez, como los rayos de sol. ¡Estallar! ¿Por qué estallar no ha de ser un ideal? ¿Qué es el arte sino un estallido? ¿Qué es, qué puede ser sino un perpetuo descalabozamiento?» (Emar, Umbral, 573). 
dan cuenta de la plana visión que en Chile se tenía de las artes. Un ejemplo de ello es la pintura de Valenzuela Llanos: «en casi ninguno veía una razón forzada para que el marco pasara por allí por donde pasa y no más acá o más allá» (Emar, Miltín 1934, 38), ironizando así sobre el entendimiento de lo sublime como totalidad inefable. Es por ello que en su texto «Frente a los Objetos» (del libro Miltín 1935, por aparecer), nuestro autor señala la necesidad de dejar atrás las ideas relacionadas con la parcelación de las entidades, en pos de lo que él llama «el mundo de la unidad, perceptible para nosotros únicamente por las relaciones, las relaciones, los 〈compromisos〉 de los objetos»(Lizama, 140). Es entonces así que la realidad ya no se nos presenta como total, sino que como fragmentada, alejada de toda pretensión de referencialidad ${ }^{14}$.

\section{LO SUBLIME AUTÉNTICO: LO IMPENSADO COMO POTENCIALIDAD DE LAS ESCRITURAS IMPOSIBLES}

La tensión entre dos maneras de entender el quehacer literario es lo escenificado en Miltín 1934. Si retomamos su trama argumental, ella se inicia con la finalidad de escribir El Cuento de Medianoche, intento que se enmarca dentro de lo que se entiende como «obra orgánica», en la cual las partes se conforman en torno a un todo armónico regido por un efecto final. Esta empresa, al interior de la novela que nos atañe, no llega a buen término y lo que hallamos más bien es una reflexión metapoética sobre su quehacer, sobre la imposibilidad de un comienzo, lo cual nos retrotrae al comentario borgiano que bien se le puede aplicar a Emar: "Macedonio me dijo que él escribía para ayudarse a pensar» (Borges, 37). La escritura, de ese modo, se delata como un abrirse al devenir del pensamiento mismo:

Bien. En todo caso es necesario escribir - ¡no! - dejar empezado el Cuento de Esta Noche.[...]/ ¡Una palabra!/ Veamos:/ 7.000.000 de frases. Ninguna me convence, no. Algo sí, lo que mañana pensaré de esto. T' en fais pas./ [...]/ Así vino esta frase. [...]/ Parece que empieza el/ Cuento de esta noche/Sigamos: /[...]/ Había una vez.../[...]. Se trata, cada noche, ebrio o no, de escribir algo, cualquier cosa, lo que caiga a la punta del lápiz./ Por el momento, no lo creo posible (Emar, Miltín 1934, 14-15).

Constatamos aquí que la narración, al ser mostración de lo «irrepresentable», de la imposibilidad de escritura, se ve forzada a recurrir a una estética del fragmento, urdida, por el procedimiento vanguardista del montaje. El discurso, en este caso de modo fracta ${ }^{15}$, muestra esa imposibilidad de compleción del reinado de la narrativa tradicional, la cual se regía por un sistema de representación orientado por una perspectiva central y un tiempo lineal, tributarios de un narrador omnisciente. Si la anterior narrativa mostraba

14 Señala nuestro autor: «¿Cómo hacer aceptar que no es únicamente lo que se ve a "primera vista» la realidad total? ¿Que todo ser, que todo objeto no es aislado y único sino un infinito comienzo de probabilidades y que marchar por ellas, lejos de alejarse de la realidad, es, seguramente, penetrarla más?» (Emar, Miltin 1934, 213-214).

15 Entendemos por fractalidad «cualquier cosa cuya forma sea extremadamente irregular, extremadamente interrumpida o accidentada, cualquiera que sea la escala en que la examinamos» (Calabrese, 136). 
la armonía entre forma y contenido, por el contrario: «lo sublime se determina como un cierto quiebre en la condición del discurso en cuanto tal, un quiebre que ocurre en el discurso y por obra del lenguaje, pero que por su mismo carácter parece exceder la potencia entre ambos. [...] Dicha tensión caracteriza a lo sublime como un movimiento [...] que, en lugar de ofrecerse diacrónicamente, se presenta en su pura instantaneidad» (Oyarzún, 20).

A su vez, esta aventura escritural vanguardista se abre a lo que en Las Palabras y las Cosas es referido como lo impensado por Michel Foucault ${ }^{16}$, término que se liga de modo indisoluble a la velocidad con que el pensamiento mismo parece abarcar(se) en su indetenible mutación, lo cual invierte el signo instrumental de la razón para inaugurar una razón en éxtasis por su apertura al infinito de lo pensable:

No sé verdaderamente en este momento si el título prometido era de Esta Noche o el que antecede. Mi pensamiento va a velocidades fantásticas. Acabo de pensar cosas que nadie podrá jamás imaginar. No por las bellezas de ellas. No. ¡Imbéciles! Por:

Relaciones, Relaciones.

Y aclaraciones...

Nada de esto tendrá significado mañana.

En ese sentido, la ausencia de significado no debe asociarse con un mero vacío; lo sublime tiene la particularidad, al no ser considerado como un concepto cerrado, fijo, de abrirse, y como se ha visto en la cita anterior, a un particular tipo de semiosis ilimitada ${ }^{17}$. Tal fenómeno, no obstante, no debe entenderse desde su contenido, desde su significado, sino que desde el pathos que genera este apremio de lo sublime, en donde: «Nada —nada como algo, nada de algo - se piensa en este pensamiento, y si cabe hablar de contenido [...], este no puede ser otro que aquel éxtasis y aquella inminencia. [...] Con él acontece el pensamiento como pura apertura a la totalidad, y en esa misma medida nos afecta, nos sobrecoge y nos exalta. El gran pensamiento sería, pues, el pensamiento afectándonos como tal apertura» (Oyarzún, 26). El vuelco deconstructivo, entonces, transita para dar cabida al significante, mas no como un mero continente de la idea de lo sublime, sino que como la forma falaz en que éste devela la verdad engorrosa de la escritura como perpetuo tránsito.

16 Para Foucault, lo impensado no se define necesariamente en relación de oposición frente a lo ya existente, sino que como matriz generadora, y siempre reactivable, de todas las esferas de lo posible: «Lo esencial es que el pensamiento es para sí mismo y en el espesor de su trabajo a la vez saber y modificación de aquello que sabe, reflexión y transformación del modo de ser de aquello sobre lo cual reflexiona» (Las Palabras y las Cosas, 318). En este caso en particular, dicha noción, en Miltín 1934, se relaciona con la fuerte exposición metafictiva respecto a lo imposible de la escritura, práctica que, a su vez, se liga a una estética de lo sublime.

17 Ello porque la cadena sígnica que aquí se gesta debe ser entendida desde lo que provoca a nivel del pathos, y no al nivel de lo referencial, ya que no se trata aquí de dar cuenta de todos los significados posibles, sino de la apertura, de la potencialidad con que aquello puede darse: «El significar del habla sublime muestra aquí su doblez, en cuanto no se le puede concebir en términos referenciales: en el esplendor de la figura, el lenguaje deja de ser un órgano a través del cual se transmita información sobre determinados estados del mundo; en él se manifiesta la verdad del mundo como aquello que nos afecta y que, afectándonos, abre ante todo nuestra comprensión para las cosas y los eventos» (Oyarzún, 41-42). Lo sublime, entonces, puede (de)finirse como límite que se sobrepasa a sí mismo. 


\section{MILTÍN 1934 Y SU RELACIÓN CON EL GLOBO DE CRISTAL: LOS ALBORES DE LA TEORÍA DE LOS FLUIDOS}

Hemos visto, hasta ahora, que la discontinuidad y fragmentariedad narrativa tiene su razón de ser en la imposibilidad de la instancia narrativa de concretar El Cuento de Medianoche. Se cierra nuestra novela con las siguientes palabras: «Así me hallaba el buen año al llegar: solo, triste, mudo, sin haber vuelto a ver al hombre Martín Quilpué, sin haber escrito el Cuento de Medianoche, y lo que es peor, ¡Oh, Dios mío!, sin haberle encontrado un rol a Fredegunda. FIN» (Emar, Miltín 1934, 224). Sin embargo en Umbral, y en particular en El Globo de Cristal, la historia de Fredegunda aparece contada, e incluso vivida, por quien será el biógrafo de Lorenzo Angol: Onofre Borneo. Este último, en su calidad de narrador, es homologable en funciones a su par en primera persona de la novela que nos convoca ${ }^{18}$. Es decir, lo que aparecía como el final de Miltín 1934 es retomado de modo discontinuo en Umbral, lo que condiciona a la totalidad de la obra emariana como un texto sin fin: es decir, en constante escritura y reescritura, ajena a todo origen y a todo cierre. Lo cual evidencia la tentativa infinita ${ }^{19}$ de nuestro autor por narrar una historia sin fin, elíptica, llena de pliegues, conexiones y resemantizaciones.

Es así que, al entender Emar el arte como praxis vital de ruptura con las formas convencionales y los clichés institucionalizados, la apuesta de Miltín 1934 es radical: «Entramos a lo esencial del arte, a una cuestión básica, a una cuestión de principios: el artista debe repetir las visiones de la vida o el artista debe volver a crear la vida. O victrola o creador» (Escritos de Arte, 137). De ahí que el proceso de escribir se transforme en una complejísima peripecia de la emergencia de una subjetividad no reificada, que busca resingularizarse por medio de la aventura del pensamiento: esto es, la apertura hacia lo impensado, lo que posteriormente veremos que en Umbral se precisará como una poética de lo fluídico-inusitado.

Es en Umbral donde aparece, de modo explícito, la noción de fluido, entendida como una esencia vivificante de todo orden. Es decir, ni las personas ni los objetos pueden entenderse como tales, salvo por causa de los fluidos, suerte de soplos de vida, que atraviesan $y$ difuminan todas las fronteras: «Por todas partes ruedan con ruidos de torrentes hundidos, comentarios de cosas... cosas... Veamos, ¿cómo llamarlas? No encuentro. Es difícil llamarlas, ¡qué decir definirlas!, porque son un aglomerado de tantos elementos diferentes, contrarios, anacrónicos. O acaso no. Porque, pensándolo bien, a lo mejor, digo yo, son concordes, son unidad» (Emar, Miltín 1934, 23-24). En la cita anterior vemos un

18 Tras saber que la historia de Fredegunda termina en tragedia - la muchacha es quemada en sus extremidades, la madre apuñala al hijo mientras éste dormía-, lo cual es vaticinado en Umbral como cierre del Día Siete, y por la aparición, a la usanza de Miltín 1934, podríamos asegurar que es aquí donde se fragua el Cuento de Medianoche de Martín Quilpué; lectura que se refuerza tanto por la referencia a Fredegunda, personaje que en Miltín 1934 no pudo ser engarzado en rol alguno, como por la aparición de Quilpué, sumado a que dicha aventura ocurre durante la noche número siete, lo que tiene un evidente sentido cabalístico, fenómeno asociado a la constante necesidad de Emar de desdoblarse en diversas instancias, tanto narrativas como actoriales. Respecto de ese tema no diremos más, para no incurrir innecesariamente en una temática que ya ha sido ampliamente discutida por varios autores (Lastra, Lizama, Brodsky, Canseco Jérez, Piña y Cantin, entre otros).

19 Piña, citando las palabras del narrador de Umbral: «Mi vida no es solo este momento; mi vida se prolonga, llena, pletórica, hacia todos lados», alude a esta imposibilidad, inasibilidad de una vida: "Irrecuperable en su totalidad experiencial (fenomenológica)» (Piña, 380). 
primer esbozo del teorizar acerca de lo indefinible. De ahí que la postura del narrador sea vacilante, respecto de si aquellos ruidos de torrentes hundidos deben ser considerados desde la dispersión o desde la unidad. Esa duda creadora de la que hablamos en páginas anteriores, en Umbral será resuelta recogiendo ambas perspectivas, por lo cual proponemos que Miltín 1934 puede considerarse una antesala de la ulterior deconstrucción practicada en Umbral, en donde ni los objetos ni las personas serán considerados como categorías ontológicamente cerradas: «Nosotros [...] solo tenemos una finalidad: buscar, coger el fluido. Nosotros consideramos objetos, personas, paisajes [...] como pantallas, como barreras que al fluido atajan para revelarlo. Si [...] por pantallas el fluido no pasa [...], ese no pasar es la única muerte [...]. Todo lo demás es [...] vida» (Emar, Primer Pilar, 291). Así, mientras en Miltín 1934 se describe apenas como una imposibilidad de (de)finición, en Umbral lo indefinible pasará a ser el fluido mismo. En otras palabras, lo inefable toma cuerpo en Umbral en calidad de dispositivo significante de la imposibilidad de captación del fluido.

De lo anterior se desprenden dos conclusiones: la primera, que la idea de la velocidad del fluido sobrepasa a la de lo pensable, lo que, a su vez, es causa del proyecto fallido de escribir el Cuento de Medianoche. La segunda, que son las características propias del fluido - su multiplicidad inapresable y su carácter inusitado- las que hacen de Miltín 1934 un corpus fragmentado en su continuidad, dando pie a diversos episodios enmarcables dentro de una estética de lo fantástico ${ }^{20}$.

\section{LO IMPENSADO Y LA ESTÉTICA VANGUARDISTA DE LO SUBLIME}

De este modo, la dificultad de dar nombre a lo que se devela como inconstante, huidizo, nos lleva a la imposibilidad del decir a causa de una metástasis del pensamiento:

Quería decirle una cosa, una sola [...] una que se hallaba, clara y nítida en mi mente. Pero apenas la tomé - a la cosa en cuestión - para darle sílabas sonoras y expelerla, la cosa evocó otra que la había originado, la cual otra despertó a todas aquellas que — por deducción las unas, por inducción las otras- la habían hecho nacer y, junto con ello vibraron todos los recuerdos a ellas asociados y se me erizaron en el cerebro más de mil signos de interrogación que destilaron a los puntos mismos bajo ellos desde sus garfios enroscados, mil respuestas simultáneas, exactas algunas como postes, más o menos exactas otras como lagunas, equivocadas, angustiadas muchas como rieles que se van, erróneas varias como adobes; pero todas [...] fueron en un instante solo una cosa que, al ser una, abarcó a la primera cosa y a la que la siguió y a los recuerdos, una cosa que fui yo pensando, no desgranadamente, sino simultáneamente [...] (Emar, Miltín 1934, 91).

20 En Miltín 1934 vemos que el narrador, elevando su campo de visión desde el cerro Miltín, declarará: «vi todo entonces cuanto aparece en ese libro y cuanto en él aparecerá y pueda aparecer. De ahí que creí justicia llamarlo con su nombre» (77). Recordemos que la clarividencia adjudicada a Miltín por la creencia popular sería el primer signo de un afán de trascendencia. Sin embargo, y sin explicación lógica alguna, una dama santiaguina recibe dichas palabras y en una esquela le recrimina: "no lo ha visto todo", para luego darle cuenta sobre su discrepancia con la censura clerical del cine. Como vemos, si unimos ambos enunciados, ellos pueden interpretarse como una mostración irónica de la imposibilidad de asir la totalidad. 
Aquellas «mil respuestas simultáneas» que «fueron en un instante solo una cosa» nos remiten a una disposición del relato en donde los comentarios metanarrativos sobre la aventura del pensamiento configuran un movimiento rizomático ${ }^{21}$. En dicho sentido, lo que Peretti, a partir de Derrida, define como differánce 22 nos ayuda a comprender lo que en Umbral será llamado no huella, sino que fluidos: "La huella no es nada, no es un ente, excede la pregunta qué es y, eventualmente, la hace posible» (Derrida, 96). Así, tenemos que la instancia narrativa se veía enfrentada a esta (in)decibilidad, la que continúa describiendo: «Y, naturalmente, yo ahora quería que ella supiese el globo, todo él, pues decirle algo que no fuese esa instantánea vibración total, me aparecía como la más abyecta mentira, ya que acababa de enterarme de que la verdadera verdad, la única, no eran ni momentos ni hechos ni nada que se mueva» (Emar, Miltín 1934, 91-92). De hecho, aquí lo que podría concebirse como huella/fluido, es (in)definido por medio de un oxímoron que condensaría toda su significación: instantánea vibración total, es decir, el absoluto contenido en un no-tiempo que prescinde de inicio y fin.

Visto desde la perspectiva deconstruccionista, el tiempo en su esencia es inaprehensible, hecho que, y en consecuencia, debilitaría la presencia, ya que la diferencia y la aplaza: «No solo ocurren otras cosas sino que yo voy a pensar otras cosas, mientras salgan de entre mis labios las largas babosas viscosas y estas otras cosas, aun cuando fuesen las mismas ya pensadas por mí en otros tiempos, serían en apariencias únicamente las mismas, puesto que las pienso no solamente en un momento diferente, sino que impelido a hacerlo por causas diferentes, y esto tendría también que explicárselo a mi mujer, de modo que... de modo que...» (Emar, Miltín 1934, 92-93). El factor temporal es aquel que agudiza la imposibilidad de captar dicha huella, entendida como esencia velocísima, en donde los afanes de dar con una verdad ontológicamente única e incuestionable se ven del todo impedidos:

Porque cualquier cosa que le diga, cualquiera — supongamos la que se me vino a la punta de la lengua al separarla de la señora de Naltagua-, ella, al oírla, va a creer que es esa para mí una cosa definitiva, una idea mía, cuadrada, aislada, una cosa que yo pienso y sobre la cual me afirmo cuando en ella pienso. ¡Y no, no! Si eso que le quería decir no es que yo lo piense, no, no, no. Yo no puedo pensar nada, yo no soy más que ese globo instantáneo $y$ permanente y lo que pueda pensar y decir, solo aspectos ínfimos vistos por un cretino a causa de la lentitud extrema de la luz que le lleva las visiones y, por lo tanto, un desenredo afanoso y pesado a lo largo del interminable bostezo de la luz que acarrea pelotillas del globo total. ¡Lógico! (Emar, Miltín 1934, 93).

El destacado se corresponde, una vez más, con el oxímoron «instantánea vibración total», donde el narrador no tiene más opción que conformarse con un lenguaje que funciona desde la negatividad, desde la ausencia de esa huella, de ese fluido que pasa. Es por ello que lo sublime se plantea como una estética de la indefinición, donde el lenguaje tiene su razón de ser en los requiebres mismos de su ausencia: «El «no〉 y el «sin» rigen en lo sublime como el signo de la nada hacia la cual oscila la totalidad de lo que es, y esta oscilación -que en su vehemencia y violencia ante todo compromete al páthos como afecto de mundo- es lo sublime» (Oyarzún, 52).

21 Para Deleuze y Guattari, a diferencia del modelo occidental del árbol, «el rizoma es un sistema acentrado, no jerárquico y no significante $[\ldots] »(52)$.

22 Entendida como «Juego de reenvíos en el que ningún elemento está presente en sí mismo» (Peretti, 112). 
Lo fluídico-inusitado daría cuenta de todos y cada uno de los fenómenos en los cuales como aliento de vida transita: «Hablar callado, hablar por la eternidad de los siglos para decirle que los siglos no son; hablar yo para que sepa ella que yo no hablo; oír ella para que sepa yo y también ella que ella no es la que oye; que no es ella ni yo ni los siglos ni nada, mas no es la nada porque todo lo es todo. Hablar así, así, así. Hablar así hasta que de la cabeza me crezcan gatos flacos maullando y a ella yerba mate de su sexo» (Emar, Miltín 1934, 94). El lenguaje, en este caso, más que como un propulsor de una mímesis de lo ya pensado, aboga por el potencial propio de lo impensado, ajustándose a lo que desde las estéticas de lo sublime se denomina como phantasía: «El recurso de la phantasía otorga un superávit de manifestación que, paradójicamente, trastroca la presencia de la cosa hasta el punto eventual de su escamoteo» (Oyarzún, 41). La huella, el fluido, la phantasía, entonces, como indicio de lo ya sido, es el único remanente de lo que desde la metafísica tradicional sería concebido como el ir tras la pesquisa de una única verdad. Por el contrario, dentro de una estética vanguardista de lo sublime - que provoca la "suspensión del efecto referencial» (Lyotard)—, comprometida en el caso de Emar con una búsqueda de lo fluídico-inusitado, el arte sólo puede optar por devenir en una suerte de precario traductor de lo indescifrable.

\section{REFERENCIAS}

Borges, Jorge Luis. Conversación Jorge Luis Borges - Oswaldo Ferrari. Diálogos. Barcelona: Seix Barral, 1992. Medio impreso.

Burger, Meter. Teoría de la Vanguardia. Barcelona: Península, 1987. Medio impreso.

Castro Morales, Belén. «Los horizontes abiertos del Cubismo: Vicente Huidobro y Pablo Picasso». Anales de Literatura Chilena 9 (2008). 149- 167. Medio impreso.

Cantin, Nadine. "Miltín 1934, una Estética del Espacio». Taller de Letras 36 (2005). 99-111. Medio impreso.

Calabrese, Omar. La era Neobarroca. Madrid: Cátedra, 1999. Medio impreso.

Deleuze, Gilles y Felix Guattari. Rizoma. Valencia: Editorial Pre-Textos, 1977. Medio impreso.

Derrida, Jacques. De la gramatología. Traducción de O. del Barco y C. Ceretti. Buenos Aires: Siglo XXI, 1971. Medio impreso.

Emar, Juan. Miltín 1934. Santiago-Caracas: Dolmen, 1997. Medio impreso. . Umbral. Primer Pilar: El Globo de Cristal. Santiago: Ediciones de la Dirección de Bibliotecas, Archivos y Museos, 1996. Medio impreso. . «Ideas sueltas sobre Literatura». Diario La Nación, 25 de junio de 1924, 5. Medio impreso.

Espinosa, Patricia. «Un Año de Juan Emar: Intertextualidades, Metatextualidades y Ontología del fragmento». Aisthesis 36 (2006). Medio impreso.

Foucault, Michel. La Arqueología del Saber. México D.F: Siglo XXI Editores, 2001. Medio impreso.

. Las Palabras y las Cosas. México D.F: Siglo XXI Editores, 1999. Medio impreso.

Oyarzún, Pablo. Razón del éxtasis. Santiago: Editorial Universitaria, 2010. Medio impreso. 
Plaza, Dino. «Tradición y vanguardia en Miltín 1934». Literatura y Lingüistica 17 (2006). Medio impreso.

Peretti, Cristina de. Jacques Derrida. Texto y Deconstrucción. Barcelona: Anthropos, 1989. Medio impreso.

Piña, Carlos. «Ser y tiempo en Juan Emar». Mapocho 60 (2006). Medio impreso.

Lizama, Patricio. "Frente a los Objetos. Fragmento de Juan Emar». Taller de Letras 26 (1998). 137-141. Medio impreso.

_. «Un año de Emar: El artista de vanguardia en una modernidad periférica». Revista Chilena de Literatura 77 (2010). Medio impreso.

Lyotard, Jean-Francois. La postmodernidad. Barcelona: Editorial Gedisa, 1999. Medio impreso.

Todorov, Tzvetan (Comp.). Teoría de los formalistas rusos. México: Siglo XXI, 2002. Medio impreso.

Subirats, Eduardo. El final de las vanguardias. Barcelona: Anthropos, 1989. Medio impreso.

Slavinski, Janusz. "Las funciones de la crítica literaria. Criterios». La Habana 32 (2004). 233-253. Medio impreso.

Wallace, David. Cavilaciones de Juan Emar. Tesis para optar al grado de Licenciado en Humanidades con mención en Lengua y Literatura Hispánica. Universidad de Chile, 2003. Medio impreso. 